\title{
A declaration of eco-ethics
}

\author{
John Cairns, Jr., EEIU Fellow* \\ Department of Biology, 1020 Derring Hall, Virginia Polytechnic Institute and State University, \\ Blacksburg, Virginia 24061, USA
}

\begin{abstract}
Eco-ethics is the essential foundation for sustainable use of the planet. Such a foundation must consist of a series of value judgments to which humanity is committed. This declaration is a tentative attempt to provide some illustrative examples.
\end{abstract}

KEY WORDS: Eco-ethics $\cdot$ Declaration $\cdot$ Web of life $\cdot$ Interdependence $\cdot$ Sustainability

Resale or republication not permitted without written consent of the publisher

The following tentative Declaration of Eco-Ethics was inspired by Professor Otto Kinne's publications (1997, 1998, 2001, 2002), which document successive steps in the development of eco-ethics. In contrast to most traditional ethics, eco-ethics is subject to progressive maturation, comments and criticism.

An initial version of this declaration will appear soon in Common Ground (Cairns in press). It is reproduced here with permission of Dr. Jeffrey Yule, Common Ground Editor. While the article has been in press, I thought of five additional statements (Nos. 13-17) that are appropriate for the declaration, and they are added to this version.

(1) We are creatures of the planet and all species are our evolutionary relatives. We acknowledge our dependence on the biospheric life support system and pledge to act in ways that enhance its integrity.

A statement of respect for the interdependent web of life is totally inadequate! Furthermore, respect does not exclude, but also does not require, stewardship and constant care and attention. An ethical life requires all of these, motivated by love. An uncharitable person might conclude that, since humans are part of the web, these feelings are a type of narcissism; however, humans are individually part of the web for a brief time on a small temporal scale.

\footnotetext{
*Email: jcairns@vt.edu
}

(2) We should value individual worth and dignity of each individual in the context of an ecological life support system with a multitude of individuals, each of whom has potential worth and value. We should deplore individual acts that diminish sustainable use of the planet and applaud and cherish acts that further this goal.

We should respect the potential worth and dignity of each individual until we see contrary evidence-not based on skin color, religious belief, age, gender, or ethnic origins, etc. However, merely having the potential does not justify unqualified endorsement unless the potential is demonstrably realized in ways that do not degrade the biosphere or endanger other individuals. More importantly, the actions eliciting respect should enhance biospheric integrity and the human condition in order to deserve genuine respect. If 
humans, individually and as a society, are unwilling to make judgments on these issues, natural selection will 'judge' them.

(3) We acknowledge that our spirituality had its genesis in nature and vow not to profane it by destroying its source. People who would argue that spirituality comes from a higher power doubtless believe nature does also, so the source is identical.

(4) We acknowledge that we are part of a living continuum and that participating in the destruction of this continuum is self-destruction.

(5) We embrace an ethical system that preserves the planet and its biosphere for all creatures of the planet as well as our descendants.

The central issue has been stated by Wilson (1984, p. 12) with his usual clarity: 'The one process now going on that will take millions of years to correct is the loss of genetic and species diversity by the destruction of natural habitats. This is the folly our descendants are least likely to forgive us.'

(6) The interdependent web of life is sacred and, thus, should be treated with reverence and care. We pledge not to endanger this system through excessive accumulation of material goods, excessive use of energy, or by usurping the place of other species to a degree that precludes their continued existence.

(7) We pledge to adjust our individual and societal behavior so that it is compatible with biospheric integrity instead of further modifying the biosphere so that our technological society can expand and grow.

(8) We pledge to view ourselves as parts of the biospheric system and behave in ways that do not block its cyclic phenomena so that the flows remain continuous.

(9) We acknowledge that human independence is an illusion! Humans have always been dependent on the interdependent web of life and will continue to be so. In the 21st century, much of society is nearly totally dependent on technology as well. Even though we depend on both systems, we worship technology and degrade the web of life. We pledge to reaffirm on a daily basis the dependence of both human society and its technology on natural systems. Interdependence is a reality and is a better conceptual model than the mistaken dichotomy of independence/interdependence. However, it is clearly more difficult to visualize and may be too great a shift in approach at this time.

(10) We acknowledge that our physical bodies will ultimately return to the biosphere and become parts of fish, insects, trees, soil, the hydrologic cycle, and the atmosphere. We pledge to cherish the biospheric shrine to which our physical bodies will return.

(11) We affirm that the only sustainable practices are cyclical and that many linear processes are unsustainable. We pledge to avoid these linear processes to the best of our ability and espouse cyclical processes that constitute the basis of the interdependent web of all life.

(12) We acknowledge that the biospheric world has existed for billions of years and that the world of anthropogenic artifacts (roads, cities, shopping malls, etc.) has only existed for a few millennia. We pledge to integrate these two worlds so that the recent one does not endanger the ancient one.

(13) We pledge to honor every individual, institution, and organization that practices eco-ethics and value this attribute more than material possessions.

(14) We vow that cultural, disciplinary, special interests, and the like will not compromise our ecoethical standards. This task is difficult but not impossible in a politically charged environment. Consensus and mutual accommodation in the quest for a harmonious relationship with natural systems will be essential.

(15) We affirm the importance of environmental education as the foundation for understanding and dialogue across barriers of discipline, culture, socioeconomic status, and politics. Environmental education provides the necessary threads to weave what Orr (1993) terms "the vessel of community," which unites specific knowledge with people, local knowledge, social structures, and ecological systems. Environmental education has, from its beginnings, emphasized both knowledge and motivation to act (Stapp et al. 1969). We now add the important concept of action competence (Breiting \& Mogensen 1999) to this mixture. Action competence turns motivation into skills and direct involvement at personal, community, national, and international levels.

(16) We vow to incorporate the precautionary principle into our decision-making processes at all levels. The precautionary principle (Raffensperger \& Tickner 1999) states that, even in the absence of conclusive scientific evidence, we shall act to protect the health of humans and the environment. In order to enable citizen participation in the decision-making process, incorporation of this principle rests upon increased citizen understanding or literacy about scientific evidence, scientific processes, risk assessment, assessment of alternatives, and basic concepts of human and ecological health and well-being. A literate public is the foundation for the democratic process and the involvement of all stakeholders.

(17) We pledge to remain optimistic about achieving sustainable use of the planet, however unattainable it may seem. Our ability to rally the world depends on an unwavering commitment to this goal. The deeply pessimistic view of human nature expressed by Thomas Hobbes' Homo Homini Lupus - every man is a wolf to every other man" - is not the path to a habitable planet. 


\section{LITERATURE CITED}

Breitling S, Mogensen F (1999) Action competence and environmental education. Cambridge J Educ 29(3):349-353

Cairns Jr J (in press) Revisiting respect for the interdependent web of life and the worth and dignity of each individual: a major issue in sustainable use of the planet. Common Ground http://commonground.umfk.maine.edu

Kinne O (1997) Ethics and eco-ethics. Mar Ecol Prog Ser 153:1-3

Kinne O (1998) Humanity can survive only with a new concept of ethics: eco-ethics. EEIU Brochure, Inter-Research, Oldendorf/Luhe

Kinne O (2001) Eco-ethics further developed text: 01.05.2001.

Editorial responsibility: Mary Batson (Managing Editor), Oldendorf/Luhe, Germany
EEIU Brochure, Inter-Research, Oldendorf/Luhe

Kinne O (2002) Eco-ethics further developed text: 01.05.2002. EEIU Brochure, Inter-Research, Oldendorf/Luhe

Orr DW (1993) Environmental literacy: education as if the earth mattered. Twelfth Annual EF Shumacher Lectures, 31 October 1992. EF Shumacher Society, Stockbridge, MA

Raffensperger C, Tickner J (1999) Protecting public health and the environment: implementing the precautionary principle. Island Press, Washington, DC

Stapp W, Bennett D, Bryan W, Fulton J, MacGregor J, Nowak P, Wan J, Wall R, Havlick S (1969) The concept of environmental education. J Environ Educ 1(1):30-31

Wilson EO (1984) Biophilia. Harvard University Press, Cambridge, MA

Submitted \& Accepted: November 13, 2002

Proofs received from author(s): November 13, 2002

Published on the web: November 18, 2002 